\title{
JOSÉ MARÍA ARGUEDAS Y LA MEMORIA AUTOBIOGRÁFICA DEL INDIGENISMO CONTEMPORÁNEO
}

\author{
José Carlos ROVIRA \\ Universidad de Alicante
}

Hay un texto de José María Arguedas que me gustaría recordar señalando con él los límites de mi reflexión. Recibía en 1968 el premio Inca Garcilaso de la Vega y concluyó su discurso así:

Contagiado para siempre de los cantos y los mitos, llevado por la fortuna hasta la Universidad de San Marcos, hablando por vida el quechua, bien incorporado al mundo de los cercadores, visitante feliz de grandes ciudades extranjeras, intenté convertir en lenguaje escrito lo que era como individuo: un vínculo vivo, fuerte, capaz de universalizarse, de la gran nación cercada y la parte generosa, humana, de los opresores. El vínculo podía universalizarse, extenderse; se mostraba un ejemplo concreto, actuante. El cerco podía y debía ser destruido; el caudal de las dos naciones se podía y debía unir. Y el camino no tenía por qué ser, ni era posible que fuera únicamente el que se exigía con imperio de vencedores expoliadores, o sea: que la nación vencida renuncie a su alma, aunque no sea sino en la apariencia, formalmente, y tome la de los vencedores, es decir que se aculture. Yo no soy un aculturado; yo soy un peruano que orgullosamente, como un demonio feliz habla en cristiano y en indio, en español y en quechua'.

' Apareció en apéndice a la última novela, El zorro de arriba y el zorro de abajo, Buenos Aires, Losada, 1971 (20ª edición), pág. 297. 
Le di muchas vueltas a este texto durante tiempo. Era por una parte el comienzo del discurso de un suicida (de hecho el escritor se suicidó algunos meses después, en 1969). Era además una síntesis desafiante del mestizaje como actitud cultural, mestizaje como conflicto en cualquier caso, no como unión ideal. Era también el testimonio del conflicto personal en un tiempo en el que José María Arguedas escribía su última obra El zorro de arriba y el zorro de abajo, aun a sabiendas de que iba a entremezclar la historia narrativa con sus diarios personales en los que iba a contar el suicidio e, incluso, en carta al rector de su Universidad, dejar escritos los preparativos para su entierro. El texto sigue produciendo escalofríos, como siempre los produce cuando alguien textualiza su propio final. Como los produjo en su día el italiano Cesare Pavese cuando terminó su diario con aquella frase «Basta de palabras. Un gesto. No escribiré más».

Intentaré asumir más adelante una reflexión que proceda de este texto, pero antes quisiera dar unos datos sobre la vida y la obra de José María Arguedas en el contexto del indigenismo.

\section{ANDAHUAYLAS, 1911}

José María Arguedas nació en 1911 en Andahuaylas, al sur del Perú. La biografía tiene una serie de momentos y lugares que pueblan posteriormente su universo narrativo, dotando de una amplia intensidad memorial a sus páginas: los viajes del padre por la sierra peruana se convierten en material inicial de Los ríos profundos; la convivencia con los indios en la infancia, obligado por la madrastra, dinamiza la experiencia fundamental del bilingüismo y de la doble cultura; San Juan de Lucanas sirve para crear el símbolo literario de la aldea de San Pedro en Todas las sangres; también Puquio, otra de las geografías infantiles, está en la base de Agua y Yawar fiesta; como los internados de la infancia, fundamentalmente el de los mercedarios de Abancay, como base de la creación del material narrativo de Los ríos..., etc.

Estamos en cualquier caso ante un escritor que ha hecho de su materia literaria una forma de autobiografía, en la que geografías y situaciones vividas van determinando los impulsos de creación. Pero sobre estos impulsos se desarrolla inmediatamente una construcción lírica que genera la mejor parte de su obra, en la que es el mundo de evocación de la infancia el que persiste, creando una especial forma de entender la realidad: la aproximación vivencial al mundo indígena, como clave que explica el Perú contemporáneo, y, para Arguedas, a partir de aquí, el mundo contemporáneo. Heredero de una tradición cultural, sobre la que tiene 
una memoria biográfica, su creación novelística se va abriendo paso entre la lengua quechua, o los cantos quechuas, como raíz de identidad, hasta el grado de ser auténticos contrapuntos emotivos-memoriales de sus tramas literarias, tan vinculadas también a la propia biografía. Sobre estas líneas avanza muy pronto la condición científica del hombre interesado en la antropología, como determinación cultural y social para su aprecio del mundo indígena.

\section{LA LENGUA Y LA EXPRESIÓN LITERARIA}

El texto que leía al principio nos plantea la realidad de dos universos lingüísticos que remiten a dos universos culturales, el quechua y el español. José María Arguedas, establecido entre los dos, vincula desde el principio su creación a una cuestión teórica de orden fundamental:

¿En qué idioma se debía hacer hablar a los indios en la literatura? Para el bilingüe, para quien aprendió a hablar en quechua, resulta imposible, de pronto, hacerlos hablar en castellano; en cambio quien no los conoce a través de la niñez, de la experiencia profunda, puede quizá concebirlos expresándose en castellano. Yo resolví el problema creándoles un lenguaje castellano especial, que después ha sido empleado con horrible exageración en trabajos ajenos. (Pero los indios no hablan en ese castellano ni con los de lengua española ni mucho menos entre ellos! Es una ficción. Los indios hablan en quechua. Toda la sierra del sur y del centro, con excepción de algunas ciudades, es de habla quechua total. Los que van de otras regiones a residir en las aldeas y pueblos del sur tienen que aprender el quechua: es una necesidad ineludible. Es pues falso y horrendo presentar a los indios hablando en el castellano de los sirvientes quechuas aclimatados en la capital. Yo, ahora, tras dieciocho años de esfuerzos, estoy intentando una traducción castellana de los diálogos de los indios. La primera solución fue la de crearles un lenguaje sobre el fundamento de las palabras castellanas incorporadas al quechua y el elemental castellano que alcanzan a saber algunos indios en sus propias aldeas. La novela realista, al parecer, no tenía otro camino².

El texto se sitúa en una larga reflexión en la que Arguedas da cuenta de la cuestión de la lengua como un problema personal, y angustioso, desde que escribiera sus primeros relatos. Nos dice así una vez:

${ }^{2}$ José María Arguedas, La novela y el problema de la expresión literaria en el Perú, en José María Arguedas, Una recuperación indigenista del mundo peruano (antología de José Carlos Rovira), Barcelona, Anthropos (suplemento 31), 1992, pág.34. 
Escribí el primer relato en el castellano más correcto y «literario» de que podía disponer. Leí después el cuento a algunos de mis amigos escritores de la capital, y lo elogiaron. Pero yo detestaba cada vez más aquellas páginas. (No, no eran así ni el hombre, ni el pueblo, ni el paisaje que yo quería describir, casi podía decir, denunciar! Bajo un falso lenguaje se mostraba un mundo casi inventado, sin médula y sin sangre; un típico mundo «literario», en que la palabra ha consumido a la obra. Mientras en la memoria, en mi interior, el verdadero tema seguía ardiendo intocado. Volví a escribir el relato, y comprendí definitivamente que el castellano que sabía no me servía si seguía empleándolo en la forma tradicionalmente literaria ${ }^{3}$.

Los textos que cito nos remiten una y otra vez a una conciencia angustiada en la que el conflicto de la lengua deviene el conflicto del estilo, recreado como drama de un escritor que estaba intentando reunir en su obra un mundo complejo del que un elemento central estaba siendo el mundo indígena. El debate se establecía con precisiones claras, con disyuntivas precisas como las que se plantea cuando supone que una excesiva regionalización de la lengua impediría a la escritura resultante la universalidad. Es evidente que escribir en quechua la aniquilaría, si el autor no se planteaba traducirse; era evidente entonces que la propuesta es la creación de una lengua que pueda ser universal, sin dejar de transmitir el alma de las palabras de lo que está construyendo, el mundo andino.

La utopía de la lengua, como explicó Alberto Escobar en su monografía sobre Arguedas ${ }^{4}$, es el conflicto y el ansia legítima que centra el mundo del escritor desde sus comienzos. Esta utopía creadora adquiere por primera vez en Arguedas resultados claros. Es común la afirmación de que fue en Los ríos profundos, sin duda la mejor novela arguediana, en la que se situaron los momentos más felices de esta creación. Porque en esta novela precisamente adquirimos una resonancia, a través de palabras quechuas que van salpicando el texto, a través de juegos con la sintaxis que crean extrañeza al lector. El esfuerzo de lenguaje de Arguedas consiste básicamente en la presencia de palabras y frases quechuas en su relato, palabras que se aclararán contextualmente o mediante la traducción ${ }^{5}$ :

\section{${ }^{3}$ Ibidem, pág. 33}

${ }^{4}$ Alberto Escobar, Arguedas o la utopía de la lengua, Lima, Instituto de Estudios Peruanos, 1984.

${ }^{5}$ Tengo en cuenta las propuestas de Juana Martínez en su edición de José María Arguedas, Los ríos profundos, Barcelona, Anaya/ Mario Muchnik, 1995.Sin embargo las citas de la obra corresponden a la edición Madrid, Alianza editorial, 1981. Sobre el léxico arguediano es fundamental el trabajo de Milagros Aleza Izquierdo, Americanismos léxicos en la narrativa de José María Arguedas, Valencia, Cuadernos de Filología-Universitat de València, (Anejo 5), 1992. 
Ejemplo 1: Presentación progresiva de una frase. Localización: Capítulo I de Los ríos profundos. Contexto: el niño se aproxima al muro incaico en el Cusco:

Me acordé, entonces, de las canciones quechuas que repiten una frase patética constante: yawar mayu, río de sangre; yawar unu, agua sangrienta; puk-tik'yawar k'ocha, lago de sangre que hierve; yawar wek'e, lágrimas de sangre. ¿Acaso no podría decirse yawar rumi, piedra de sangre, o puk'tik yawar rumi, piedra de sangre hirviente? Era estático el muro, pero hervía por todas sus líneas y la superficie era cambiante, como la de los ríos en el verano, que tienen una cima así, hacia el centro del caudal, que es la zona temible, la más poderosa.

-iPuk'tik yawar rumi!- exclamé frente al muro, en voz alta.

(Rios..., 18)

Ejemplo 2: Traducción. Localización: Capítulo VII. Rebelión de las chicheras:

Las mujeres gritaron:

-¡Kunami suakuna wañunk'aku! (¡Hoy van a morir los ladrones!)

Cuando volvieron a repetir el grito, yo también lo coreé.

(Ríos..., 117)

Ejemplo 3: Aclaración contextual (en este caso también onomatopéyica) y modificaciones del orden sintáctico de la frase. Localización: capítulo IX. Ernesto pregunta a una de las chicheras si han matado a Doña Felipa, la cabecilla de la insurrección, como le ha dicho un soldado

¿Cierto han matado a doña Felipa?-le pregunté a la mestiza mirándola a los ojos.

-Jajayllas! ;Jajayllas!-gritó ella; se rió-. Soldado borracho seguro sueña -dijo-. ¡Borracho es borracho! ¡Ándate de aquí, niño! -me empujó.

(Ríos...185)

Podríamos reiterar ejemplos que respondan a este sistema de aclaración de los quechuismos del texto, mediante la presentación progresiva del sentido de una 
frase, la aclaración contextual o la traducción, o señalar la modificación del orden sintáctico como indicativa del habla indígena, o recordar las numerosas veces en que cantos quechuas, con la traducción confrontada, aparecen en la obra como contrapunto memorial de las situaciones que nos va narrando. Los procedimientos han sido analizados varias veces y no pretendo por supuesto sentar plaza de especialista en este argumento, sino señalar los que parece que Arguedas consiguió con su obra.

El argumento lo ha explicado mejor que nadie en un trabajo excepcional (y también excepcionalmente manipulador por otras cuestiones) Mario Vargas Llosa quien en La utopía arcaica. José María Arguedas y las ficciones del indigenismo ${ }^{6}$ dedica un brillante epígrafe a lo que llama «El castellano amaestrado», para decirnos que:

El narrador, bilingüe, traduce al castellano lo que algunos personajes dicen en quechua, incluyendo a veces en cursiva dichos parlamentos en su lengua original. No lo hace con demasiada frecuencia, de modo que las incrustaciones lingüísticas quechuas no estorben la fluencia narrativa, pero sí con la periodicidad necesaria para configurar el ambiente de sociedad dividida en dos pueblos, dos lenguas y dos culturas. Y no por ser «correcto», fraguado dentro de los parámetros de la sintaxis y la morfología ortodoxas, es el castellano del narrador menos apropiado para sugerir, con poderoso aliento, cuando se expresan los quechua-hablantes o se hace referencias a la cultura mágico-religiosa de los indios, la existencia de la otra lengua, la que determina una forma de relación con el paisaje y la historia distinta de la implicada en el castellano.

Lo explicó también como trabajoso proceso de creación el propio José María Arguedas:

El desgarramiento, más que de los quechuismos, de las palabras quechuas, es otra hazaña lenta y difícil. ¡Se trata de no perder el alma, de no transformarse por entero en esta larga y lenta empresa! Yo sé que algo se pierde a cambio de lo que se gana. Pero el cuidado, la vigilia, el trabajo, es por guardar la esencia. Mientras la fuente de la obra sea el mismo mundo, él debe brillar con aquel fuego que logramos encender y contagiar a través del otro estilo, del cual no estamos arrepentidos a pesar de sus raros, de sus nativos elementos?

Y reafirmó que aquella lucha había sido otra manera de buscar la universalidad de los textos:

${ }^{6}$ México, FCE, 1996, págs.176-177.

${ }^{7}$ La novela y el problema de la expresión literaria en el Perú, pág. 34. 
¿Fue y es esta una búsqueda de la universalidad a través de la lucha por la forma, sólo por la forma? Por la forma en cuanto ella significa conclusión, equilibrio, alcanzado por la necesaria mezcla de elementos que tratan de constituirse en una nueva estructura [...] Haber pretendido expresarse con sentido de universalidad a través de los pasos que nos conducen al dominio de un idioma distinto, haberlo pretendido en el transcurso del salto; esa fue la razón de la incesante lucha. La universalidad pretendida y buscada sin la desfiguración, sin mengua de la naturaleza humana y terrena que se pretendía buscar sin ceder un ápice a la extensa y aparente belleza de las palabras

Fue Rubén Darío el que desde otra tradición, desde la tradición simbolista recuperada por el modernismo, nos explicó que las palabras debían pintar el color de un sonido para apresar así el alma de las cosas. Arguedas, desde otra tradición, desde el realismo, pretendió crear con su esfuerzo una sinestesia andina que fuera capaz de dar cuenta de un mundo diferente. $Y$ el quechua subyacente era imprescindible para su ejercicio. Y creo que consiguió rotundamente hacerlo en algunos momentos. De los momentos en los que no lo consiguió -justo a partir de Los ríos profundos- voy a hablar más tarde.

Lo que sí consiguió también fue crear un clima memorial en el que los dos mundos alcanzan elementos muy eficaces de contraposición. He reiterado varias veces la rotundidad del capítulo I de Los rios profundos, como para no volver a utilizarlo aquí como ejemplo de esa contraposición eficaz.

En ese capítulo hay un espléndido recorrido en el interior de una memoria en conflicto, en la que el paseo del niño Ernesto por el Cuzco, acompañado por su padre, permite una síntesis sobresaliente de los dos universos enfrentados: el muro incaico, vivificado y transmisor de vida ( «la corriente que entre él y yo iba formándose», pág. 11, «este muro puede caminar; podría elevarse a los cielos o avanzar hacia el fin del mundo y volver», pág. 13), frente al interior de la catedral, mortificadora y trasmisora de muerte:

La luz filtrada por el alabastro de las ventanas era distinta de la del sol. Parecía que habíamos caído, como en las leyendas, a alguna ciudad escondida en el centro de una montaña, debajo de los mantos de hielo inapagables que nos enviaban luz a través de las rocas [...]El rostro del Crucificado era casi negro, desencajado, como el del pongo. Durante las procesiones, con sus brazos extendidos, las heridas profundas, y sus cabellos caídos a un lado, como una mancha negra, a la luz de la plaza, con la catedral, las montañas o las calles ondulantes, detrás, avanzaría ahondando las aflicciones de los sufrientes, mostrándose como el que más padece, sin cesar... (pág. 24)

\footnotetext{
${ }^{8}$ Ibidem.
} 
Hay aquí una interiorización, rigurosamente biográfica, de esa apertura de las «puertas de la memoria» que se desarrolla en el capítulo citado con el brillante juego del sonido de la campana de la catedral, la «María Angola», como indicio mayor de una realidad agobiante en la que el niño protagonista encuentra elementos naturales como salvación:

Me despedí del pequeño árbol. Frente a él, mirando sus ramas escuálidas, las flores moradas, tan escasas, que temblaban en lo alto, temí al Cuzco. El rostro del Cristo, la voz de la gran campana, el espanto que siempre había en la expresión del pongo [...]me oprimían. En ningún sitio debía sufrir más la criatura humana. La sombra de la catedral y la voz de la «María Angola» al amanecer, renacían, me alcanzaban. Salí. Ya nos íbamos. (pág. 25).

Y concluye con su encuentro con el río, donde la vida son insectos zumbadores, o la misma voz poderosa de la corriente que, de nuevo, entre ternura y espanto, es capaz de despertar los «primitivos recuerdos, los más antiguos sueños».

La naturaleza permite así sus evocaciones, rodeadas de una intimidad en la que no parece caber ninguna objetividad descriptiva. Se describe intimizando el paisaje, realizando con él, las más de las veces, un ejercicio de la memoria, que puede devenir memoria simbólica, en la que el antropólogo aparece al lado del niño que se crió en una cocina indígena de Puquio, construyendo paisajes en una actitud que va hacia el propio pasado y, más allá, al pasado racial, al pueblo quechua. Los mecanismos de la memoria pueden tener toda esta, múltiple, complejidad narrativa, asumir un universo indígena vivido y pensado luego, un universo emotivo e intelectual, en el que la magia, por ejemplo, se convierte en una racionalidad sustancial. «El socialismo -dice una vez Arguedas- no mató en mí lo mágico», como constatación del propio universo defendido hasta la última racionalidad mítica y mágica, la identificadora del pasado.

\section{PARA UNA REDEFINICIÓN DEL INDIGENISMO ARGUEDIANO}

Hay un valioso trabajo de la profesora Carmen Alemany Bay en el que se analizan las transformaciones que se operan en los años sesenta en el panorama de la narrativa indigenista ${ }^{9}$, centrando en Arguedas, entre otros, aquella elaboración que nos permite hablar de neoindigenismo, frente al agotamiento de la insistencia narrativa indigenista. Se hace referencia en este trabajo a algunos textos

${ }^{9}$ Carmen Alemany, «Revisión del concepto de neoindigenismo a través de tres narradores contemporáneos", José María Arguedas. Indigenismo y mestizaje cultural como crisis contemporánea hispanoamericana (coordinación: José Carlos Rovira), Barcelona, Anthropos, 1992, págs. 74-76. 
principales y se cita por ejemplo la conciencia de transformación que el propio Arguedas quiso dar desde su aventura literaria:

Entonces, cuando llegué a la Universidad leí los libros en los cuales se intentaba describir a la población indígena: los libros de López Albújar y de Ventura Calderón. Me sentí tan indignado, tan extrañado, tan defraudado que consideré que era indispensable hacer un esfuerzo por describir al hombre andino tal como era y tal como yo lo había conocido a través de una convivencia muy directa ${ }^{10}$.

Esta vocación de verdad tiene efectivamente los procedimientos y los debates que antes he señalado. La búsqueda de una lengua y un estilo para dar cuenta de dos mundos contrapuestos me parece la novedad articulatoria más importante de la transformación que se opera en esos años. Hay otras y se puede recurrir, por ejemplo, al panorama que trazó Antonio Cornejo Polar para hablar del neoindigenismo ejemplificando en Manuel Scorza: la presencia del llamado realismo mágico, la nueva complejidad formal, la intensificación del lirismo, la vinculación de un nuevo espacio determinado por las nuevas realidades indígenas parecen características que nos permiten hablar de un nuevo proceso" ${ }^{\prime \prime}$.

Cuando Arguedas, en otro texto principal, Razón de ser del indigenismo en el Perú ${ }^{12}$, pasa revista a las tradiciones culturales y la confrontación entre hispanistas e indigenistas, nos lleva a una tradición ideológica que responde a la razón de ser de dos ámbitos que son irreconciliables por las realidades sociales que representan. Pero él mismo rechaza una y otra vez la etiqueta de indigenista para su literatura. Tiene una razón de peso y es que él no está intentando dar una visión parcial del Perú contemporáneo.

La novela Todas las sangres es el intento mayor, en 1964, de abrir una perspectiva que dé cuenta del Perú de la sierra y la costa, del indio y del criollo. La novela se fragmenta en realidades múltiples que, creo, no consigue ajustar por lo que resulta además un fracaso. Pero sobre todo resulta un intento de articular realidades contrapuestas, produciéndonos la idea de fracaso el hecho de que nunca alcance la eficacia lingüística y poética de Los ríos profundos. Y probablemente no alcance tampoco la coherencia narrativa que consiga trabar la novela. La obra,

"José María Arguedas y A. Romualdo, «Poesía y prosa en el Perú contemporáneo", Panorama actual de la literatura latinoamericana, Madrid/ La Habana, Centro de investigaciones literarias, 1971, pág. 199. Citado por Alemany.

" «Sobre el "neoindigenismo" y las novelas de Manuel Scorza», Revista Iberoamericana, L, 127, 1984, págs. 549 ss.

${ }^{12}$ José María Arguedas, Una recuperación indigenista..., págs. 36-40. 
publicada en 1964, es un ambicioso y confuso proyecto de plasmación de la realidad peruana. La fundación de un espacio geográfico, la ciudad de San Pedro, trasunto literario probable de San Juan de Lucanas, del Departamento de Ayacucho ${ }^{13}$ sirve de soporte para realizar una amplísima narración conflictiva de la sociedad en la que confluyen y se entrechocan elementos de la realidad contemporánea, con una indagación hacia el pasado y su peso determinante en el presente, que permite entrever el intento de reflexión globalizante: la pobreza, el mundo indígena campesino, el mundo industrial de la ciudad, etc. permite determinar una galería de tipos y conflictos en el interior de una ciudad aniquilada por el tiempo, cuyos signos de desgate material construyen también una simbólica de la historia aniquilada en la perspectiva del Perú contemporáneo. Los grupos sociales (señores, comuneros, obreros, patronos, etc.) son parte de una galería de tipos morales que entrañan un profundo pesimismo social, en el que el mismo conflicto adquiere la función de ser paralizante. La idealización del Perú indígena, serrano, andino, adquiere un valor sobresaliente, frente a la plasmación de las crisis contemporáneas en el Perú costeño e industrial, que significan ya no sólo un enfrentamiento de mundo y lenguas, sino de clases, en estructura ideológica que determina la construcción y la narración novelesca. El recurso a la Arcadia, como ha señalado Vargas Llosa, en la plasmación del universo indígena es «una nostalgia desesperada por un mundo perdido, que se acababa, ya en gran parte destruido, y al que en su fuero interno, en contra de sus convicciones, en contra de su razón, se sentía profundamente ligado» ${ }^{14}$.

El diseño último de la variación que Arguedas imprime al indigenismo -lo que la crítica llama neoindigenismo- tiene que ver con el propósito de Los ríos profundos, con el propósito de narración de dos mundos en conflicto y no en mestizaje entendido éste como idealidad. Los recursos de lengua y de actitudes ante el mundo que construyó no son mestizos, sino que están profundamente diferenciados. Arguedas da cuenta a veces de fusiones culturales en cuanto fusiones sincréticas, incluso advirtiendo rotundamente acerca del carácter de determinadas fusiones culturales. Recurramos de nuevo al ejemplo. Nos dice una vez:

Sin embargo, ambas culturas, la criolla y la india, se mantienen profundamente diferenciadas en su médula y evolucionan paralelamente. Sobre la base de los materiales de la doctrina y cosmogonía católicas, los pueblos nativos

${ }^{13}$ La localización del espacio real, transmitida por el propio Arguedas, la da Sara Castro Klaren, El mundo mágico de José María Arguedas, Instituto de Estudios Peruanos,1973, pág. 157, obra en que se realiza un sugerente análisis de la novela.

${ }^{14}$ Mario Vargas Llosa, «José María Arguedas, entre la ideología y la Arcadia», prólogo a Todas las sangres, Madrid, Alianza Tres, 1982, pág. xi. 
crean mitos cosmogónicos posincaicos. Así, para los indios de la hacienda Vicos hubo dos humanidades: una bárbara, de individuos descomunalmente fuertes que hicieron caminar las piedras arreándolas con azotes para construir grandes monumentos líticos; esta humanidad, que era antropófaga, fue creada por el dios Adaneva. Pero Adaneva violó a una mujer muy bella y, cuando la vio preñada, la arrojó de su casa. Esa mujer fue la Virgen María y el hijo que nació de ella, Téete Mañuco (Padre Manuel, el niño Manuelito, o sea, Jesús). Téete Mañuco destruyó la humanidad bárbara mediante una Iluvia de fuego y creó la humanidad actual, físicamente más débil pero «con más pensamiento». Téete Mañuco es ya siempre joven (desventuradamente), porque cada año muere un día viernes y resucita el sábado. El cielo es exactamente como la tierra poblada por las criaturas hechas por Téete Mañuco; la diferencia consiste en que allá los indios se convierten en señores, $y$, los que en este mundo son señores todopoderosos, en el cielo hacen de indios, pero para toda la eternidad ${ }^{15}$.

La leyenda es sincrética en el sentido etimológico del término, en el sentido de impostura, en el de unión de dos contrarios contra un tercero. Van a perder los señores finalmente en esta perseverancia católica y animista al tiempo. No, no hay un mestizaje ni ideal ni pacífico. Hay una esencial heterogeneidad como propuesta teórica (dos culturas, la criolla y la india, profundamente diferenciadas y que evolucionan sin converger).

Ésta es la relevancia de Arguedas: la diferenciación de discursos y la contraposición de los mismos. Esta fue su aventura literaria que radicalizó sus posiciones culturales progresivamente.

Creo entonces, sintetizando este punto, que la transcendencia de Arguedas está en su capacidad en crear un discurso conflictivo, por tanto no mestizo, sino heterogéneo. La noción de heterogeneidad a la que me remito es la que Antonio Cornejo Polar elaboró en sus últimos años para matizar las insistencias mestizas y transculturadas de la crítica latinoamericana ${ }^{16}$.

${ }^{15}$ Razón de ser del indigenismo..., en José María Arguedas, Una recuperación indigenista... pág. 39.

${ }^{16}$ En una precisión breve de la noción, Cornejo Polar debatió los conceptos próximos de mestizaje y transculturación. Sobre el primero de ellos, observó cómo «la categoría de mestizaje es el más poderoso y extendido recurso conceptual con que América Latina se interpreta a sí misma". Este recurso, sin un esfuerzo teórico de definición, «en gran parte reproduciría una cierta ansiedad por encontrar algo así como un locus amoenus en el que se (re)conciliaban armoniosamente al menos dos de las grandes fuentes de la América moderna: la hispana y la india, aunque en ciertas partes, como el Caribe, se incluyera por razones obvias la vertiente de origen africano". Afincados en esta noción, más en el campo de la política que en el de la literatura, se trataba con ella de asumir «un punto de encuentro no conflictivo (...) para pensar-imaginar la nación como un todo más o menos armónico y coherente". Vinculando a continuación la idea de transculturación, en las formulaciones de Fernando 
En la heterogeneidad de Arguedas asumimos un papel minucioso de elaboraciones que quizá terminaron conduciendo a ninguna parte. En la década posterior a la escritura de Los ríos profundos, el escritor vivió muchas peripecias personales que le llevaron a no terminar voluntariamente aquel decenio. Muchas amarguras también. Relato telegráficamente algunas: los sinsabores que la polémica con Julio Cortázar supuso a Arguedas porque lo ninguneaba como escritor regionalista frente al universalismo de los narradores del boom (1968); la emergencia de períodos de depresión y de la vieja obsesión por el suicidio intentado por primera vez en 1966; la crisis emocional por su divorcio con Celia Bustamante (1965) y su matrimonio con Sybila Arredondo (1967); la confesión manifiesta de su crisis psicológica de la que se trató durante tres años en Chile con la psiquiatra Hoffmann, datos que van apareciendo en los diarios que introdujo en su ultima novela, El zorro de arriba y el zorro de abajo; también, y quizá sobre todo, el agotamiento de la escritura, sobre el que nos dice una vez que es el resultado de que se le han acabado los temas de la infancia, y nos narra en los diarios intercalados en los siguientes términos:

Pero ahora no puedo empalmar el capítulo III de la nueva novela, porque me enardece pero no entiendo a fondo lo que está pasando en Chimbote (escenario de la novela) y en el mundo. Voy a transcribir en seguida -lo haré al margen- las páginas que escribí en Chimbote, cuando igual que hoy, luego de varias noches de completo insomnio, atosigado ya de odios e ilusiones, de impotencia y vacío, decidí, otra vez, suicidarme [...] Entonces agonizaba porque no podía escribir el segundo capítulo; ahora se trata del tercero. El segundo capítulo lo escribí, arrebatado, sin conocer bien Chimbote ni conocer como es debido ninguna ciudad de ninguna parte. A través simplemente del temor y

Ortiz y Ángel Rama, se preguntaba si no sería esa noción «el dispositivo teórico que ofrece una base epistemológica razonable al concepto (que considero fuertemente intuitivo) de mestizaje".La propuesta de Cornejo surgía de intentar «formular otro dispositivo teórico que pudiera dar razón de situaciones socio-culturales y de discursos en los que la dinámica de los entrecruzamientos múltiples no operan en función sincrética sino, al revês, enfatizan conflictos y alteridades": «En una primera versión el concepto de heterogeneidad trataba de esclarecer la índole de procesos de producción discursiva en los que al menos una de sus instancias difería, en cuanto filiación socio-étnico-cultural, de las otras. Mas tarde «radicalicé» mi idea y propuse que cada una de esas instancias es internamente heterogénea". Los términos del debate se harán entonces intensos, puesto que Cornejo se afincará en una realidad cultural y literaria problematizada y conflictiva, para considerarla centro de cualquier visión que quiera dar cuenta de los procesos y las relaciones de la literatura en el marco de una sociedad concreta. La perspectiva contraria, todo lo que pretenda debilitar el conflicto discursivo (entre literatura hegemónica, literatura popular, literaturas indígenas) será una suerte de mistificación teórica. Como material clave para este debate, las intervenciones de Cornejo Polar, Roberto Fernández Retamar y otros en Asedios a la heterogeneidad cultural. Libro de homenaje a Antonio Cornejo Polar (José Antonio Mazzotti y U. Juan Zevallos cordinadores), Philadelphia, Asociación Internacional de Peruanistas, 1996. 
la alegría no se pueden conocer bien las cosas [...] Y creo que el intento de suicidio, primero, y luego las ansias por el suicidio fueron tanto por el agotamiento -estoy luchando en un país de halcones y sapos desde que tenía cinco años- como por el susto ante el miedo de tener que escribir sobre lo que se conoce sólo a través del temor y la alegría adultos, y no en el zumbar de la mosca que uno percibe apenas el oído se forma [...] ¡Tengo miedo, no puedo comenzar este maldito capítulo III, de veras! ¿Cuántas veces hemos hablado de él, doctora Hoffmann? (pág. 95)

Pero, en fin, dejemos a los psicoanalistas que interpreten estas cuestiones, y no nos metamos en algo que no nos interesa. Recordemos un último párrafo del escritor, perteneciente al ensayo que he citado varias veces, La novela y el problema de la expresión literaria en el Perú, en donde dice:

Pero los dos mundos en los que están divididos estos países descendientes del Tahuantinsuyo se fusionarán o separarán definitivamente algún día: el quechua y el castellano. Entretanto, el vía crucis heroico y bello del artista bilingüe subsistirá. En relación a este grave problema de nuestro destino he fundamentado en un ensayo mi voto a favor del castellano.

El via crucis de Arguedas acabó la mañana del 28 de noviembre de 1969 en la Universidad agraria de La Molina disparándose dos tiros en la cabeza. Quizá no supo que estaba acabando también con la propuesta más rigurosa de renovación del indigenismo en la literatura. $\mathrm{O}$ a lo mejor sabía que ésta, por múltiples razones, había muerto ya al comienzo de ese decenio. 